\section{Journal homepage:http://www.journalijar.com Journal DOI: 10.21474/IJAR01}

\section{RESEARCH ARTICLE}

INTERNATIONAL JOURNAL

OF ADVANCED RESEARCH

ISSN NO. 2320-5407

\title{
AlternationofCCl 4 -Induced Oxidative Stressand Nephrotoxicity by Omega-3 in Female Albino Rats.
}

Hawzheen K. Othman ${ }^{1}$ and Tahseen A. Abdullah ${ }^{2}$.

1. MSc. Biology, Physiology/ College of Science/ University of Salahaddin - Erbil.

2. MSc. Histophysiology, Lecturer, Health prevention department/Medical Technical Institute/ University of polytechnic-Erbil, Iraq.

\section{Manuscript Info}

\section{Manuscript History:}

Received: 10 May 2016

Final Accepted: 13 June 2016

Published Online: July 2016

Key words:

Omega-3-Fatty acids, Carbon

tetrachloride, Free radicals,

Malondialdehyde.

*Corresponding Author

\section{Abstract}

In the present study, twenty one female albino rats were used and they were divided in to three groups. This was carried out and designed to study the effect of omega 3 poly unsaturated fatty acid on carbon tetrachloride $\left(\mathrm{CCl}_{4}\right)$ induced oxidative stress and kidney damage in female albino rats. However, the antioxidant activity of omega-3 were determined by assessing biochemical parameters (serum creatinine, urea, uric acid, and malondialdehyde(MDA)). Carbon tetrachloride caused significant increase inserumcreatinine, urea, uric acid, and MDA levelwhile, omega 3 significantly prevented the increase of the serum levels of creatinine, urea, uric acid, and MDA.

Hawzheen K. Othman.

Copy Right, IJAR, 2013,. All rights reserved.

\section{Introduction}

Free radical is an atom or ionpossessing an unpairedelectron that can be considered as fragments of molecules, these unpaired electrons make free radicals very reactive towards other substances, or even towards themselves: (Chessman and Slater, 1993).It was generally accepted that free radical seek to pair with a new free electron, and free radicals would be generate andit is unstable and can react with another one to generate a new free radical. Thus, this chain reaction of free radical subsequently damage biological systems and tissues (Ozbek, 2012)

However, reactive nitrogen species (RNS), reactive oxygen species(ROS)and their generation are two kinds of biologically active free radicals, their generation, chemical reactions, and in vivo effects are closely interrelated. Harman was the first person who recognized the pathogenic role of oxygen free radicals in diseased states (Jeng and Fan-fan, 2012). The studies of free radical and antioxidants in biology demonstrated that free radical played a role in chronic diseases including atherosclerosis, cancer (Lobo et al., 2010) neurodegenerative (e.g. Parkinson's disease, Alzheimer's disease, multiple sclerosis) (Aruoma, 2003), asthma and diabetes (Florence, 2014).

Exposure to heavy metals, ultraviolet (UV) radiation,environmental pollutants, drugs, cigarette smoking, alcohol consumption(Sahreen. et al.,2012)and xenobiotics e.g., CCl4 (Kim.,et al 1990)lead to metabolic activation of ROS, which inturn causes cellular injuries (Khanet al., 2012).

Carbon tetrachloride intoxication in animals is an experimental model that generates oxidative stress in many pathophysiological states(Saber.,et al2012). The long term CCl4 exposure generates reactive oxygen species and different free radicalsin many tissues such as liver, heart, kidney, brain, lung and blood. Also, it defects antioxidant enzymes activities and increased thiobarbituric reactive substances concentrations (Théophileaet al., 2006). Inaddition, (Mohammedet al, 2013) reported that CCl4, distributes at greater concentrations in the kidney than in the liver and it has a high affinity to the cortex part of kidney which contains cytochrome P-450 predominantly.

Epidemiological studies investigate that certain that long chain highly unsaturated omega 3-fatty acids which derived from the tissues of oil fish are known to reduce the oxidant status of various tissues.Diet rich in long chain omega-3fatty acids has been shown to help in the development of healthy brain, heart and immune system 
(Meganathan., et al 2014). Omega-3 fatty acids are considered as strongantioxidant and have an anticancer role in most of the human malignancies (Abdou and Hassan, 2014). Furthermore, regular consumption of omega-3 fatty acids, particularly docosahexaenoic acid, has been reported to ameliorate cardiovascular disorders, including endothelial dysfunction, platelet aggregation, elevated blood pressure and triacylglycerols, and arrhythmia(AbdelMoneim et al., 2014).

The present investigation was conducted to study the evaluatethe mechanism of omega-3 fatty acids on kidney function test parameters in $\mathrm{CCl} 4$ induced nephrotoxicity in female albino rats.

\section{Experimental animals:-}

Twenty one adult female albino rats (Rattusnorvegicus) were used in the present study. Animals bred in the animal house of Biology Department, College of Science, Salahaddin University. All rats were weighing about 150-250 gms and 9-12 weeks old. The experiments achieved under the standard laboratory conditions (12h light: 12h dark photoperiod) and $22 \pm 4 \mathrm{C}^{\circ}$, the animals were supplied with standard rat diet and tap water ad libitum.

\section{Experimental design:-}

One experiment was carried out and designed to study the effects of omega-3 fatty acid on malondialdehyde (MDA) and some renal function test parameters including serum creatinine, urea and uric acids) in $\mathrm{CCl} 4$ induced nephrotoxicity in female albino rats.

The experimental rats were divided into three groups, each with seven individuals and the treatments were continued for 4 weeks.

The group one received standard rat chaw and tap water (Maulood, 2005) and represents control rats. The rats in the second group received $\mathrm{CCl}_{4}(0.25 \mathrm{~mL} / \mathrm{kg})$ body weight intraperitoneally and normal rat chaw with tap water. The rats in third group received standard rat chow supplemented with omega-3 $(1 \mathrm{gm} / \mathrm{Kg})$ body weight and intraperitoneally administration of $\mathrm{CCl} 4(0.25 \mathrm{~mL} / \mathrm{kg})$ bodyweight.

\section{Samples collection:-}

Collection of blood samples:-

The rats were anesthetized using a combination of ketamine hydrochloride $(35 \mathrm{mg} / \mathrm{kg})$ and xylazine $(5 \mathrm{mg} / \mathrm{kg})$ (Liard et al., 1996). Blood samples were taken by cardiac puncture into chilled tubes with EDTA (4.5 $\mathrm{mM}$ as an anticoagulant) and centrifuged at $+4 \mathrm{C}^{\circ}$ for 15 minutes; then plasma was stored at $-80^{\circ} \mathrm{C}$ (Sony, Ultra low, Japan).

\section{Determination of serum malondialdehyde (MDA):-}

Serum malondialdehyde (MDA) concentration, one of the end products of lipid peroxidation, was determined by the method of Wallinet al. (1993). The level of serum MDA was determined spectrophotometrically. In brief: To $150 \mu$ lserum sample the followings were added: $1 \mathrm{ml}$ of $17.5 \%$ trichloroacetic acid (TCA) and $1 \mathrm{ml}$ of $0.66 \%$ (TBA), mixed well by vortex, incubated in boiling water for 15 minutes, and then allowed to cool. One ml of 70\% TCA was added and the mixture was allowed to stand at room temperature for 20 minutes, and then centrifuged at $2000 \mathrm{rpm}$ for 15 minutes, and the supernatant was taken for scanning spectrophotometrically at $532 \mathrm{~nm}$.

The concentration of MDA calculated as follow:

$\operatorname{MDA}(\mu \mathrm{mol} / \mathrm{L})={ }^{\text {Absorbance at 532nm } \times \mathrm{D}}$.

$$
\mathbf{L} \times \mathbf{E} 0
$$

L: light path $(1 \mathrm{~cm})$

$\mathrm{E}_{0}$ : Extinction coefficient $1.56 \times 10^{5} \mathrm{M}^{-1} \cdot \mathrm{Cm}^{-1}$

D: Dilution factor $=1 \mathrm{ml}$ Vol. Used in ref./0.15 $=6.7$

\section{Biochemical determination:-}

\section{Determination of serum creatinine:-}

Serum creatinine level was determined by spectrophotometerCreatinine kit(Biolab, France). Creatinine in alkaline solution reacts with picrate to form a coloured complex; the intensity of the colour is proportional to the concentration of the creatinine in the serum and urine. The absorbance was measured at $500 \mathrm{~nm}$ using spectrophotometer. 


\section{Determination of serum uric acid:-}

Serum uric acid was determined by uricase method, using colorometric test kit and the absorbance was measured at $492 \mathrm{~nm}$ using spectrophotometer (Biolab,France).

\section{Determination of serum urea:-}

Serum urea was determined by using colorometric test kit and the absorbance was measured at $600 \mathrm{~nm}$ using spectrophotometer (Biolab,France).

\section{Statistical analysis:-}

Analysis of data was performed by using \{statistical package for social science (SPSS) version 24\}. Results are expressed as mean \pm standard error (mean $\pm \mathrm{SE}$ ). Statistical differences were determined by Ducan's test for multiple comparisons after analysis of variance (ANOVA).

\section{Results:- \\ Serum MDA:-}

The serum MDA level of $\mathrm{CCl}_{4}$ treated rats increased significantly and reached $(10.939 \pm 1.3 \mu \mathrm{mol} / \mathrm{L})$ as compared with control rats $(4.206 \pm 1.1 \mu \mathrm{mol} / \mathrm{L})$. While, serum MDA level decreased significantly in animals that were provided with diet supplemented with omega-3 $(6.418 \pm 0.5 \mu \mathrm{mol} / \mathrm{L})$, compared with $\mathrm{CCl}_{4}$ treated rats (Table1 and figure 1).

\section{Serum uric acid level:-}

Statistical analysis revealed significant increase in serum uric acidlevel $(14.61 \pm 7.05 \mathrm{mg} / \mathrm{dL})$ of $\mathrm{CCl}_{4}$ treated rats when compared with control group $\left(9.99 \pm 0.55 \mathrm{mg} / \mathrm{dL}\right.$ ). On theother hand, rats treated with (omega-3 and $\mathrm{CCl}_{4}$ ) showed significant decreases in serum uric acid $\left(9.61 .96 \pm 0.71 \mathrm{mg} / \mathrm{dL}\right.$ ) compared to $\mathrm{CCl}_{4}$ treated rats (Table.1 and figure 2 )

\section{Serum urea:-}

Carbon tetrachloride caused significant increase in serum urea level $(31.12 \pm 0.76 \mathrm{mg} / \mathrm{dL})$ when compare with control rats $(21.00 \pm 0.48 \mathrm{mg} / \mathrm{dL})$. on the other hand, rats treated with(omega-3 and $\mathrm{CCl}_{4}$ ) showed significant decreases in serum urea $(23.57 \pm 0.64 \mathrm{mg} / \mathrm{dL})$ when compare withCCl4 treated rats(Tabe. 1 and figure 3$)$.

\section{Serum creatinine:-}

Carbon tetrachloride caused a significant elevation in serum creatinine level $(147.43 \pm 24.2 \mathrm{mg} / \mathrm{dL}) \quad$ inCCl $_{4}$ treated rats when compared with control rats $(42.52 \pm 10.5 \mathrm{mg} / \mathrm{dL})$, while, serum creatinine level significantly decreased when rats treated with $\mathrm{CCl}_{4}$ and omega $3\left(65.64 \pm 6.1 \mathrm{mg} / \mathrm{dL}\right.$ ) when compared with $\mathrm{CCl}_{4}$ treated rats (Tabe1 and figure 4).

\section{Discussion:-}

Treatment with $\mathrm{CCl} 4$ for days elevated serum MDA level. MDA has been reported to one of the secondary products produced following exposure toreactive oxygen species and free radicals, and it can be used to check out oxidative damage through measuring serum levels of thiobarbituric acid reactive substance (Lee et al., 2012). However our results confirm those of (Ganieet al., 2011) as they concluded that, CCl4 enhances lipid peroxidation through increases free radical formation. $\mathrm{CCl} 4$ is metabolize by cytochrome $\mathrm{p}-450$ and produce highly reactive free radical which initiates lipid peroxidation of the endoplasmic reticulum s cell membrane and causes a chain reaction.

Our results were correlated with (Attia and Nasr 2009) who reported that omega-3 caused significant reduction in lipid peroxidation induced by CCl4 in different organs of rats. The decrease in the MDA level by fish oilmay be due to its antioxidant properties. Omega-3 could maintain normal levels of Superoxide dismutase andcatalase activities (Pauwels andKostkiewicz, 2008) Inaddition,the anti inflammatory and anti-oxidant properties of omega-3 may be through it is ability to inhibiting lipid peroxidation and scavenging of free radicals (Abdou and Hassan, 2014).

The present results reveal that, intoxicated rats with $\mathrm{CCl} 4$ showed a significant increase in serum creatinine, urea and uric acid levels as compared to normal control rats. These pathological changes indicate the potential damage to kidney cells induced with $\mathrm{CCl} 4$ treatment since the observed increase is indication of an impairment of glomerular function and renal disorder (El-bazet al., 2015). Our results are agree with earlier reports reported by (Lotfy, 2009), who attributed these increases to the pathological changes observed in the kidney tissue and to the damage in kidney 
glomeruli as a result of CCl4 injection. Moreover (Diabet al., 2014) recorded that CCl4 induced elevation in serum urea could be related to the impairment of renal blood follow as well as reduction in glomerular filtration rate. However, creatinine production, infact, has a strong relationship with muscle mass and increased it is level indicates the muscular wasting occurred during $\mathrm{CCl}_{4}$ intoxication (Banfi and Del Fabbro, 2006). Although, CCl4 causes depletion and deamination of muscle proteinsbut associated renal disorder prevents normal excretion process and therefore, causes accumulation and elevation serum levels of creatinine and urea (Rahmatet al., 2014).

Oral administration of omega-3 produces significant nephroprotective effects in $\mathrm{CCl} 4$ intoxicated rats. Our results are in agreement with (Shaheenet al., 2016) who suggest thatOmega-3 may find clinical application in a different condition where cellular damage is a result of oxidative stress. The nephroprotective effects of omega-3 may be explained by the antioxidant effect of omega- 3 fatty acids. The antioxidant or anti-inflammatory effects of omegathrough inhibiting lipid peroxidation and scavenging of free have been reported previously (Abdouand Hassan, 2014). However, omega-3 protects rat from CCl4 induced kidney injury as evident from significant decrease in serumcreatinine, urea and uric acid Changizet al., (2012) suggested thatthe ameliorative effects of omega-3 on kidney function may be due to the improvement of glomerular filtration. Moreover, it was generally accepted that fish oil reduce hyperlipidemia by decreasing serum total cholesterol and low density lipoproteincholesterol concentration, so, creatinine might be decreased due to glomerulosclerosis reduction (Lauretaniet al., 2009). In addition, in a study (Abdel-Moneim et al., 2014) demonstrated that elevated serum level of creatinine, urea and uric acid were improved in the hypothyroid treated rats with fish oil, they concluded that the protective effects of omega3 in in the concentration of creatinine, uric acid and urea may due to that omega- 3 ameliorated concentration of thyroid hormones and improved glomerular filteration.

\section{Conclusion:-}

In conclusion, from this study it was concluded that omega-3-fattyacids, protects the kidney against CCl4 induced nephrototoxicity in female albino rats.

Table 1:-Effects of omega-3on serum MDA, uric acid, urea and creatinine in CCL4 induced oxidative stress and nephrotoxicity in female albino rats

\begin{tabular}{|c|c|c|c|c|}
\hline \multirow[b]{2}{*}{ Treatments } & \multicolumn{4}{|l|}{ Parameters } \\
\hline & $\begin{array}{l}\text { MDA } \\
(\mathrm{m} \mu \mathrm{ol} / \mathrm{L})\end{array}$ & $\begin{array}{l}\text { Uric acid } \\
\text { (mg/dL) }\end{array}$ & \begin{tabular}{|l} 
Urea \\
(mg/dL)
\end{tabular} & $\begin{array}{l}\text { Creatinine } \\
(\mathrm{mg} / \mathrm{dL})\end{array}$ \\
\hline Control & $4.206 \pm 1.1^{\mathrm{a}}$ & $9.99 \pm 0.55^{a}$ & $21.00 \pm 0.48^{\mathrm{a}}$ & $42.52 \pm 10.5^{a}$ \\
\hline $\begin{array}{l}\text { CCl4 } \\
(0.25 \mathrm{~mL} / \mathrm{kg})\end{array}$ & $10.939 \pm 1.3^{b}$ & $14.61 \pm 0.5^{b}$ & $31.12 \pm 0.76^{b}$ & $147.43 \pm 24.2^{b}$ \\
\hline Omega-3(1gm/Kg)+CCL4(0.25 mL/kg) & $6.418 \pm 0.5^{\mathrm{a}}$ & $9.61 .96 \pm 0.71^{a}$ & $23.57 \pm 0.64^{a}$ & $65.64 \pm 6.1^{a}$ \\
\hline
\end{tabular}

The same letters mean non significant differences while the different letters mean significant differences

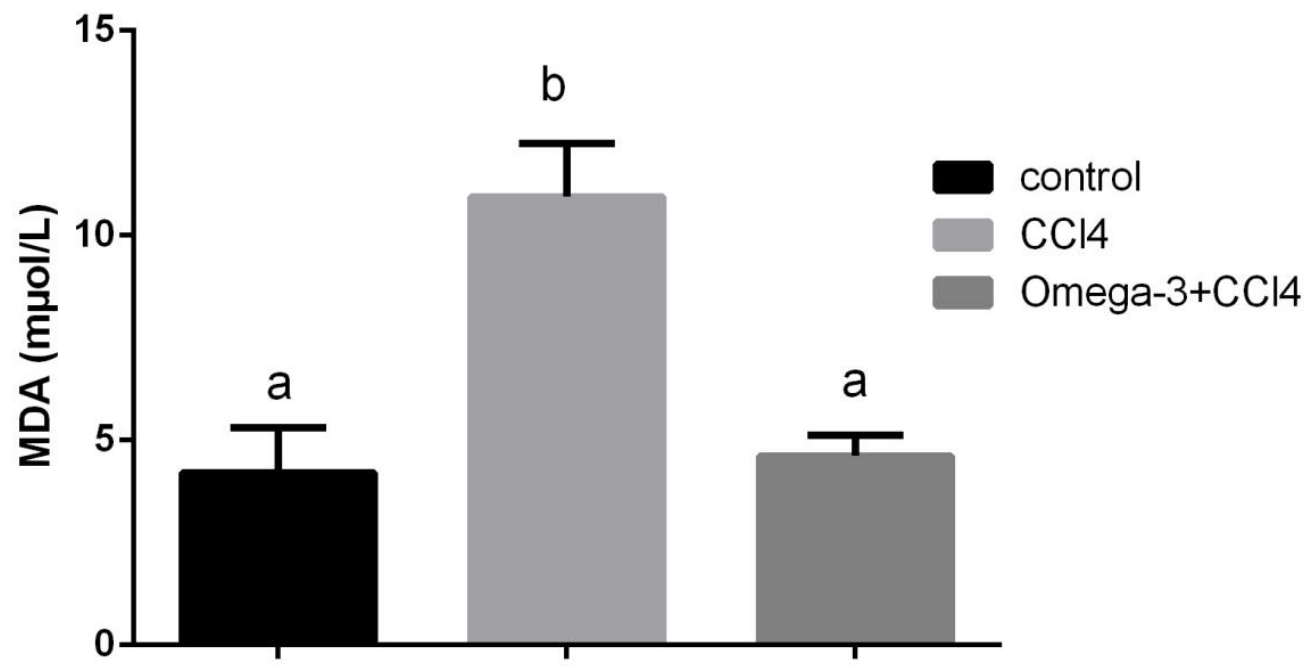

Figure 1:-Effects of omega-3 on MDA in CCl4 induced nephrotoxicity. The CCl4 treated rat group was compared with control while omega-3 treated rat group was compared with $\mathrm{CCl} 4$ group. 


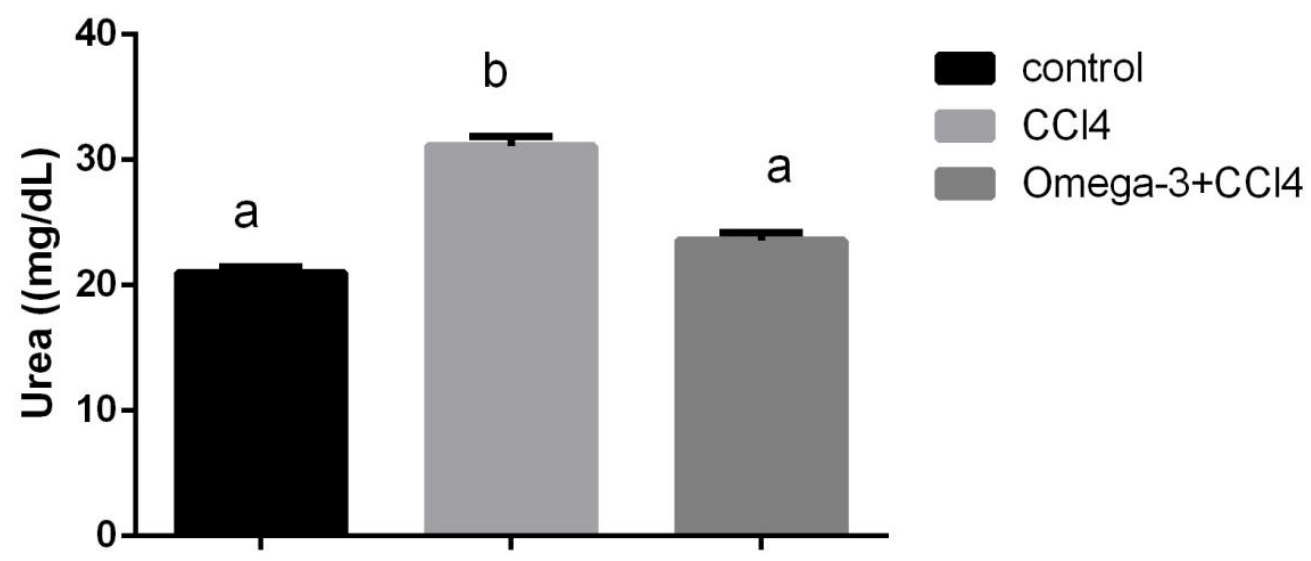

Figure 2:-Effects of omega-3 on uric acid in $\mathrm{CCl} 4$ induced nephrotoxicity. The $\mathrm{CCl} 4$ treated rat group was compared with control while omega-3 treated rat group was compared with $\mathrm{CCl} 4$ group.

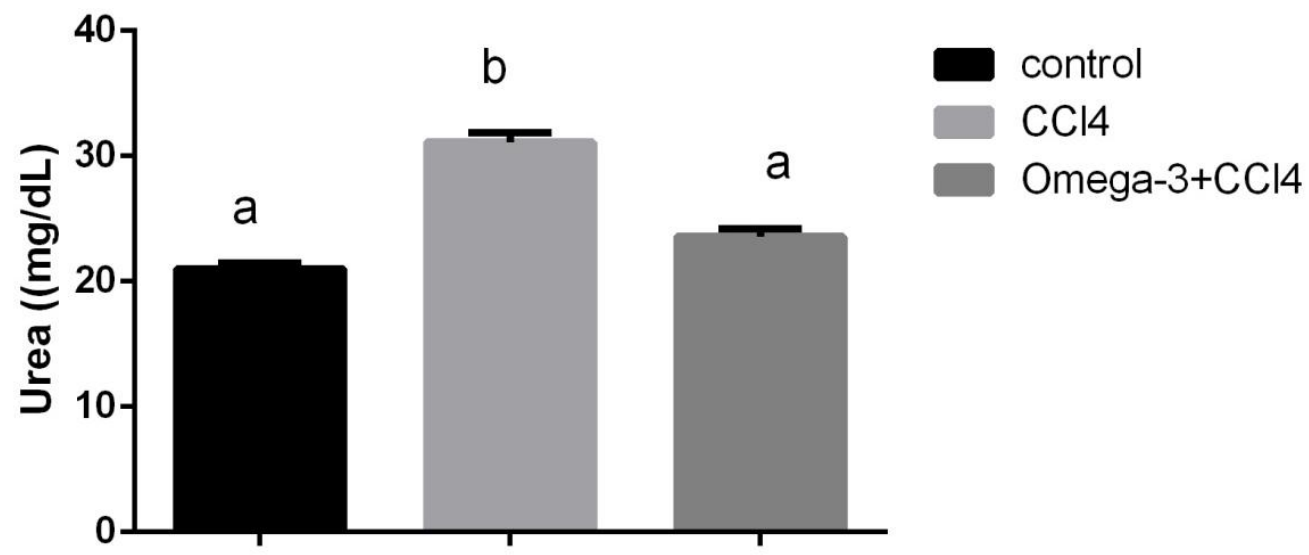

Figure 3:-Effects of omega-3 on urea in $\mathrm{CCl} 4$ induced nephrotoxicity. The $\mathrm{CCl} 4$ treated rat group was compared with control while omega-3 treated rat group was compared with $\mathrm{CCl} 4$ group.

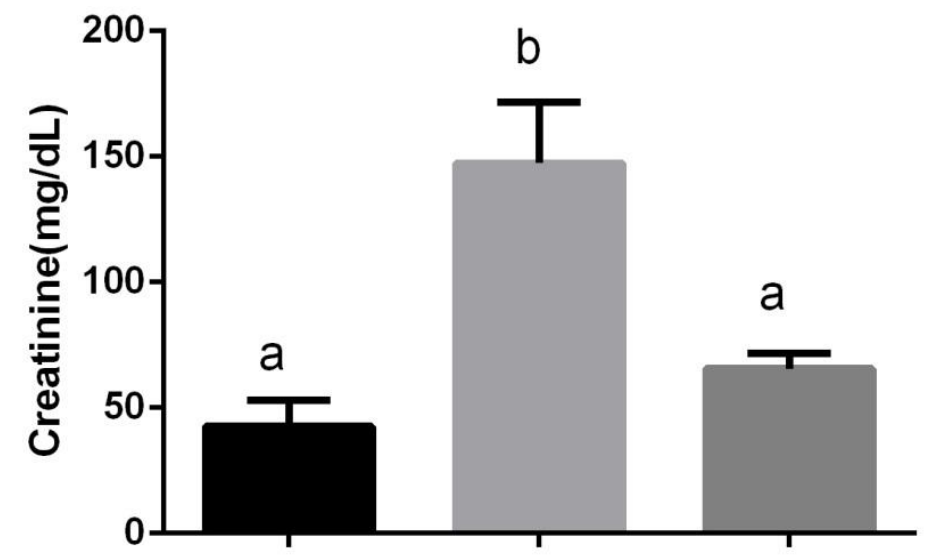

Figure 4:-Effects of omega-3 on creatinine in $\mathrm{CCl} 4$ induced nephrotoxicity. The $\mathrm{CCl} 4$ treated rat group was compared with control while omega-3 treated rat group was compared with $\mathrm{CCl} 4$ group. 


\section{References:-}

1. Abdel-Moneim, A., Mahmou., B. and Mahmoud, R. (2014). The effect of fish oil supplementation on the liver and kidney functions of hyperlipidimic and hypothyroid albino rats. International journal of biopharma research., 3 (6): 114-119.119

2. Abdou, H.M. and Hassan, M.A. (2014): Protective Role of Omega-3 Polyunsaturated FattyAcid against Lead Acetate-Induced Toxicity in Liver and Kidney of Female Rats. BioMed Research International.,1-11.

3. Aruoma., O.I. (2003): Methodological considerations for characterizing potential antioxidant actions of bioactive components in plant foods. Mutation Research/Fundamental and Molecular Mechanisms of Mutagenesis., 523(524): Pages 9-20.

4. Attia, A.M. and Nasr, H.M. (2009): Evaluation of protective effect of omega-3 fatty acids and selenium on paraquat intoxicated rats. Slovak J. Anim. Sci., 42(4): 180 - 187.

5. Banfi, G. and Del Fabbro, M. (2006): Relation between serum creatinine and body mass index in elite athletes of different sport disciplines. Br J Sports Med., 40(8): 675-678.

6. Behar-Cohen, F.F., Heydolph, S., Faure, V., Droy-Lefaix, M.T., Courtois, Y., Goureau, O.(1996): Peroxynitrite cytotoxicity on bovine retinal pigmented epithelial cells in culture. BiochemBiophys Res Commun., 226:842849.

7. Changiz, S., Najafi, A.H., Kabirinia, K., Vahedi,E. and Jamebozorky, L. (2012): Oral Omega-3 Fatty Acid for Reduction of Kidney Dysfunction Induced by Reperfusion Injury in Rats. Iranian Journal of Kidney Diseases., 6(4): 275-283.

8. Cheeseman, K.H.and Slater, T.F. (1993): An introduction to free radical biochemistry. Br Med Bull., 49(3):48193.

9. Diab, A.A., Aziz, S.A., Hendawy, A.A. and Salim, D.M.M. (2014):The ameliorative effect of lcarnitine on experimentally induced liver cirrhosis in male albino rats. Journal ofAmerican Science., 10,: 8-18

10. EL-BAZ, F.K., ALY, H.F. and SAAD, A.A. (2015): Extract improves carbontetrachloridein induced nephrotoxicity and inflammation in rats. Int J Pharm Bio Sci., 6(4): $146-157$.

11. Florence, T.M. (2014): The role of free radicals in disease. Physiol Rev., 94(2): 329-354.

12. Ganie, S.A., Haq, E., Hamid, A., Qurishi, Y., Mahmood, Z., Zargar, B.A., Masood, A. and Zargar, M.A. (2011): Carbon tetrachloride induced kidney and lung tissue damages and antioxidant activities of the aqueous rhizome extract of Podophyllumhexandrum. BMC Complement Altern Med., 11: 17.

13. Jing, N. and Fan-fan., H. (2012): Role of reactive oxygen species in the renal fibrosis. Chin Med J., 125(14):2598-2602.

14. Khan, R.A., Khan, M.R., Sumaria, S. (2012): $\mathrm{CCl}_{4}$-induced hepatotoxicity: protective effect of rutin on p53, CYP2E1 and the antioxidative status in rat. BMC Complementary and Alternative Medicine.,12(178):2-6.

15. Kim, H.J., Odendhal, S., Bruckner, J.V. (1990): Effect of oral dosing vehicles on the acute hepatotoxicity of carbon tetrachloride in rats. ToxicolApplPharmacol., 102:34-49.

16. Laird, K., Swindle M. and Fleckneell, P., (1996). Rodent and rabbit medicine.Firsteddition.BPCwheatons Ltd, Exeter U.K.

17. Lauretani, F., Maggio, M., Michelassi, S., Ruggiero, C., Ceda, G.P., Bandinelli, S. and Ferrucci L. (2009): Omega-3 and Renal Function in Older Adults. Curr Pharm Des.,15(36):4149-4156.

18. Lee, R., Margaritis, M., Channon, K.M. and Antoniades, C. (2012): Evaluating Oxidative Stress in Human Cardiovascular Disease: Methodological Aspects and Considerations. Curr Med Chem., 19(16): 2504-2520.

19. Lobo, V., Pati, A. and Chandra, N. (2010): Free radicals, antioxidants and functional foods: Impact on human health. Pharmacogn Rev., 4(8): 118-126.

20. Lotfy, M.M., Ph.D. Thesis. (2009): (Pharmacology) presented to Faculty of Veterniary Medicine, Zagazig University.

21. Maulood, I.M. 2005. Effects of L-arginine and Melatonin on Plasma Endothelin-1 level in Rats with Induced Diabetes Mellitus or Pulmonary Fibrosis. Ph.D Dissertation, Salahaddin University-Erbil

22. Meganathan, M., MadhanaGopal, K., Sasikala, P.,Mohan,I.J., Gowdhaman, I.N., Balamurugan, K.,. Nirmala,P., Santhakumari, S. and anitha Samuel, V. (2011): Evaluation of Hepatoprotective Effect of Omega 3-Fatty AcidagainstParacetamol Induced Liver Injury in Albino Rats. Global Journal of Pharmacology., 5 (1): $50-53$.

23. Mohammed, A.Y., Ramzi, M., Mansour, A., Al-Dosari, M., Al- Musayeib, N., Al-Sohaibani, M., Mohammed, K.P., Raftulla, S. (2013): Attenuation of $\mathrm{CCl}_{4}$-Induced Oxidative Stress and Hepatonephrotoxicity by Saudi Sidr Honey in Rats. Attenuation of $\mathrm{CCl}_{4}$-Induced Oxidative Stress and Hepatonephrotoxicity by Saudi Sidr Honey in Rats. Evidence-Based Complementary and AlternativeMedicin., VolumeArticle ID 569037, 1-10.

24. Ozbek., E. (2012). Induction of Oxidative Stress in Kidney. International Journal of Nephrology., 2012:1-9. 
25. Pauwels, E. K. J. andKostkiewicz, M. (2008): "Fatty acid facts, part III: cardiovascular disease, or, a fish diet is not fishy," DrugNews and Perspectives., 21(10): 552-561, 2008.

26. Rahmat, A.A., Dar, F.A. and Choudhary, I.M. (2014). Protection of CCl4-Induced Liver and Kidney Damage by Phenolic Compounds in Leaf Extracts of Cnestisferruginea (den Candolle).Pharmacognosy Res., 6(1):19-28.

27. Saber, A. S. and Hawazen, A. L. (2012): Protective Effect of Rosemary (RosmarinusOfficinalis) Leaves Extract on Carbon Tetrachloride -

28. Sahreen., S. Khan., M.R., Khan., R. and Alkreathy., H.M. (2012). Protective effects of Carissa opaca fruits against CCl4-induced oxidative kidney lipid peroxidation and trauma in rat. Induced Nephrotoxicity in Albino Rats. Life Science Journal.,9(1) 779-785.

29. Shaheen, A., Abeer, A.A., Zaki., H.F., Nada, S.A. and El-Denshary, A.E. (2016): The impact of omega-3 and saccharomyces cerevisiae on Amikacin-induced nephrotoxicity in rats. Der PharmaChemica., 8(1):223-234.

30. Théophilea, D., Emerya,T.D., Paul Désiréa, D.D., Véroniqueb, P.B. and Njikama, N. (2006): Effects of ALAFIA MULTIFLORA stapf on lipid peroxidation and antioxidant enzyme statuse in carbon tetrachloride-treated rats.Pharmacologyonline., 2 :76-89. 